\title{
A 4-year review of psychiatrists' participation in prosecutorial workshops on criminal capacity
}

Carla Kotze, MB ChB, DMH (SA), FCPsych (SA), MMed (Psych)
Paul Henry de Wet, BChD, MB ChB, MMed (Psych)

Forensic Unit, Weskoppies Hospital, and Department of Psychiatry, University of Pretoria

Objective. The objective was to review psychiatric involvement in seven prosecutorial workshops on criminal capacity between 2004 and 2009. The aim was to evaluate the changing role of the psychiatrists in the workshops in order to identify areas in forensic psychiatry where prosecutors have a specific need for training, and to identify more suitable methods of training.

Method. The workshop programmes, copies of presentations, the number of attending prosecutors at each workshop, informal personal notes from the presenters, suggestions from meetings in preparation for workshops and formatted feedback reports were reviewed. Information from a total of seven workshops was reviewed and interpreted by 2 psychiatrists from Weskoppies Hospital Forensic Psychiatry Unit (WHFPU).

Results. The psychiatrists' involvement increased over the years. Problematic topics that were identified include nonpathological criminal incapacity, child psychiatry and the different roles of the psychiatrist and the psychologist in court. Exposure to practical aspects, interactive workshops with case presentations, discussion groups and audience participation seemed to be the preferred method of training. Attitudes of prosecutors towards psychiatry improved with increased knowledge and understanding of the field, and overall the training was rated as relevant and enriching.

Conclusion. Psychiatrists can offer valuable training opportunities to legal professionals about the major mental illnesses and how they can affect criminal capacity, but evaluation of the training should be an ongoing process to address changing needs. Training sessions provide an opportunity for reciprocal sensitisation between the different fields. The ultimate goal is to work towards improved association between the criminal justice and mental health systems.

For many centuries there has been an interface between psychiatry and the law, and although both the law and forensic psychiatry have undergone significant changes and progression, considerable misunderstandings remain between the two fields.' Many of these misunderstandings became evident to psychiatrists from the Weskoppies Hospital Forensic Psychiatry Unit (WHFPU) during participation in prosecutorial workshops. Psychiatric participation has been requested at prosecutorial workshops on criminal capacity from 2004 until the present. This request for participation came from the Justice College, a branch of the Department of Justice and Constitutional Development. The workshops were attended by prosecutors from all provinces in South Africa.

From the onset the psychiatrists from WHFPU questioned the psychiatrist-prosecutor collaboration as presenters and facilitators at the workshops. During yearly WHFPU preparation for these workshops the presentation methods, content and topics were addressed. The needs of the attending prosecutors, how they understood and applied the information presented and the suitability of the training were also considered during the yearly preparation. Furthermore, it was observed that the psychiatric input in the workshops had increased significantly and that the presentation format had changed over the years. Because of these observations and the misunderstanding and differences noted, it was decided in 2009 to review all formal and informal knowledge that was derived from this participation.

Until very recently there has not been any formal training programme or examinations for forensic psychiatry in South Africa. At the start of this review it was envisaged that a formal course for psychiatrists to specialise in forensic psychiatry would be introduced in the near future, and this happened when a certificate in forensic psychiatry as a sub-specialty was approved by the College of Medicine of South Africa in May 2010. A comparable situation seems to exist with regard to the training of court professionals on mental disorders. In South Africa court professionals appear to receive limited formal training in mental disorders and how they affect criminal capacity. From the literature no formal guidelines or specific training methods or requirements that involved psychiatrists training prosecutors could be sourced. ${ }^{2,3}$

It became clear from the literature that mental health professionals are often called on by the legal system to testify as expert witnesses in a wide variety of cases and that the association between the legal and psychiatric professions is not as effective as it should be. ${ }^{4}$ The problem of relating law to psychiatry, according to Scheele's article 'The medical expert and the prosecutor', is the different focus of attention of each field. Whereas diagnosis and therapy in individuals is the focus of psychiatry, the legal protection of society is the focus of the criminal justice system.' In addition to this problem, various concepts in law differ from those used in clinical language and it remains difficult for the psychiatrist to navigate the barriers of communication with the legal profession. The American Academy of Psychiatry and the Law also highlights this when it mentions in its ethical guidelines that psychiatry and law have each developed their own policies, procedures, values and vocabulary. This creates areas of potential conflict, misunderstanding and abuse. The preciseness of scientific 
terminology is often achieved at the cost of clarity of meaning, and terms may have an entirely different connotation when used in lay language. It is therefore always important to explain terms to the court in lay terminology to prevent loss of the scientific meaning and to translate psychiatric knowledge into understandable opinions. ${ }^{5,6}$ This lack of common ground was highlighted in a survey done in Canada in 2000 that showed a general lack of familiarity among psychiatrists and lawyers with many of the key provisions of the Criminal Code governing mentally disordered offenders.' From the WHFPU experience this problem does not seem to be limited to Canada.

The principal aim of reviewing knowledge derived from the workshops was to identify more suitable methods of training and to enable programme and presentation adjustments that will ultimately improve the shared knowledge and understanding between the two fields. In addition, it was hoped to identify areas in forensic psychiatry where prosecutors experience problems and request a specific need for training. Lastly, this review aimed to look into the changing role of the psychiatrists in the workshops on criminal capacity over the years of participation.

\section{Method}

The psychiatrists from WHFPU who were presenters and facilitators during sessions of the prosecutorial workshops on criminal capacity gathered information on their involvement over a 5-year period (2004 - 2009). The Unit was not involved in the 2005 workshop. The information captured consisted of workshop programmes, copies of WHFPU presentations, the number of attending prosecutors at each workshop, and formatted feedback reports. In addition informal personal notes were captured together with noted suggestions made on meetings between the presenting psychiatrists in preparation for an oncoming workshop. The information sources are summarised in Table I.

The workshop programmes and WHFPU presentations at each successive workshop were compared with each other and changes in the programmes, presentations and who presented were listed. Specific attention was paid to the psychiatrists segment of the presentation time in relation to that allocated to other professionals and the number of participating psychiatrists per workshop.
The formatted feedback reports were evaluated during the 4 years of involvement with the workshops, and important or recurrent points were highlighted. These highlights together with all gathered information were categorised and compared.

Information from a total of seven workshops was reviewed. The available information was conceptualised and interpreted by two psychiatrists from the WHFPU.

\section{Results}

The psychiatric involvement in the 2004 workshop took the form of a single lecture during a 5-day workshop. The presentation by the psychiatrist was, on request from the Justice College, on the topic of 'Non-pathological criminal incapacity' (NPCI) (defined in Table II). The rest of the week was dedicated to lectures by advocates and other legal professionals.

WHFPU's involvement has progressed from this single lecture on $\mathrm{NPCl}$ to a broad spectrum of psychiatric topics and involvement for 3 of the 5 days of the workshops. After 2006 the psychiatrists facilitated 3 days with adjusted presentations that were grouped into major psycho-legal issues, for example 'Mood disorders and the law', 'Cognitive disorders and the law', etc. In addition case studies and practical examples of real court cases were added. The presentations by legal professionals have decreased over the years. Since 2007 only one day is used for presentations by legal professionals and one other day is dedicated to investigative psychology, presented by a psychologist who is not affiliated to the WHFPU. The participants also visit Weskoppies Psychiatric Hospital at the end of the workshop. During the visit to the psychiatric hospital, workshop participants are exposed to the structure and routine of an observation ward and the rehabilitation process. Here attention is paid to the more

Table II. Non-pathological criminal incapacity

Non-pathological criminal incapacity refers to situations in which the accused's alleged incapacity was of relatively brief duration and where he/she acted 'involuntarily' in the absence of a pathological mental disturbance. The lack of capacity is caused by extrinsic factors, such as a blow to the head, administration of a drug or even provocation. NPCI is recognised by the courts as a defence and it is for the Court to decide on the question of the accused's capacity, but different courts have given conflicting judgments and inconsistency is a common thread.

\footnotetext{
Table I. Information sources

Workshop programmes

Copies of WHFPU presentations

Formatted feedback reports

Informal personal notes

Suggestions

Printed programmes presented at the workshop with information on the venue, dates, presentation topics, presenters and presentation time schedule

Printed copies of the presentation slides showing the scope and detail of the topics

A formatted document presented to the delegates which they anonymously completed and handed back to the organisers. The feedback contained rating of the workshop, topics and presenters. It also included comments sections Impressions, issues, questions and problems that were noted during the workshop sessions and kept by the presenting psychiatrists

Suggestions made at preparation meetings for oncoming workshops relating to topics, presentation format, and presenters
} 
practical aspects of arranging referrals and admissions, administrative procedures and the observation process.

The workshops were initially aimed at newly appointed prosecutors and started off with small groups of between 10 and 15 people. Over the years the workshops grew in popularity, more senior prosecutors also started to attend, and the numbers swelled to groups of up to 40 prosecutors. From 2008 the workshop was presented more than once a year.

The workshop structure, topics covered and adjustments incorporated into the programme between 2004 and 2009 are summarised in Table III.

In the written feedback there were differences in the requested and problematic topics between the different workshop groups as well as between different prosecutors attending the same workshop. An example of this is that some participants would request more time to be spent on children and the law, while others would request less time to be spent on this topic.

Written requests from the first workshop were for more psychiatric topics to be discussed. Requests for child psychiatry and general psychology, more clarity on the different roles of psychiatrists versus psychologists and more detail on NPCI followed in the following workshops, as well as a reference on cultural issues and criminal capacity. Suggestions for additional topics, or that more or less time be devoted to a topic, varied in the feedback. Most delegates requested that more time be allocated to court-specific examples and case studies. Duplication and overlap on topics presented by the psychologists were noted in the last two workshops.

Involvement of an experienced legal expert and a 'mock court' with role play with the psychiatrists was suggested in the formatted feedback reports. The participants felt that this would help them lead and cross-examine an expert witness more successfully.

Following the introduction of a visit to Weskoppies Hospital Administration Department, observation ward and rehabilitation wards, more detailed discussions about specific practical procedures with examples of referral methods and administration procedures were requested. This included how to complete referral forms, training on report writing, and video training onn how an observation is done and what the observation process entails. The aforementioned requests were persistent during all the workshops. It was also requested that more time should be spent at Weskoppies Hospital with a focus on practical issues and that psychiatrists from other regions should be involved to highlight different approaches. Many suggested that the visit to Weskoppies Hospital should be at the beginning of the week to give a more hands-on approach.

Overall the participants rated the training as relevant to their work and an enriching experience. The most frequent requests and suggestions from the formal written feedback are summarised in Table IV.
The psychiatrists' impressions at the workshops and discussions during preparation for them, together with the written feedback, played a major part in the changes to the structure of the workshop programme and presentations.

From the onset of the workshops the presenting psychiatrists noted that the delegates do not easily grasp conference-style lectures and concept definitions. Introducing more practical examples and posing questions from the psychiatrists' side during the presentation elicited more audience response and facilitated discussion. In addition more time had to be allocated for questions and answers and to explain difficult concepts. It was also found better to group major psychiatric entities rather than concentrate on specific psychiatric disorders.

After the abovementioned changes and input at the 2006, 2007 and March 2008 workshops the impression remained that it was difficult to get active discussions going with more spontaneous group involvement. The active involvement was considered important to be able to conceptualise the delegates' understanding of the presentations. The introduction of real court case studies related to the psychiatric topics from the September 2008 workshop onwards improved group involvement. However, doing case studies without a theoretical background was found to be problematic. The prosecutors needed some background about psychiatric disorders, the signs and symptoms that a psychiatrist evaluates, and the course of an illness before there could be valuable discussion of case studies. Combining short presentations on basic theoretical concepts with case study discussions was introduced in the May 2009 workshop and found to be beneficial.

During the workshops certain topics were identified as problematic areas by the prosecutors and the psychiatrists. NPCl and personality disorders were two of these topics. Even after extensive discussion certain differences of opinion remained on the exact role of the psychiatrist. Input, guidance and co-facilitation by an experienced senior prosecutor at the last reviewed workshop helped with clarifying some legal issues. The need for guidance on how to prosecute/cross-examine an expert witness within the context of the psychiatric involvement at the workshop, as noted in the written feedback as well as by the WHFPU presenters, must still be addressed in future workshop programmes.

Another area of uncertainty noted was differences in the approach of psychiatrists and psychologists towards forensic evaluations and the specific roles in court of the two professions. This was the reason for the inclusion of two psychologists from Weskoppies Hospital in the last two reviewed workshops. Their input clarified many questions surrounding the different roles of the two professions.

The visit to a psychiatric facility, with specific focus on improvement of liaison between the disciplines through exposure to the practical aspects and conditions in the hospital, was noted to be well received. One problem identified, which has not been addressed, 


\begin{tabular}{|c|c|c|c|c|}
\hline Workshop & Involvement & WHFPU presenter(s) & Psychiatric topics & Changes incorporated \\
\hline September 2004 & 1 lecture & 1 psychiatrist & $\mathrm{NPCl}$ - requested & First year of involvement \\
\hline 2005 & Unit not involved & & & \\
\hline \multirow[t]{7}{*}{ October 2006} & \multirow[t]{7}{*}{1 day } & \multirow[t]{7}{*}{1 psychiatrist } & General psychiatric definitions & More topics were introduced \\
\hline & & & Classification systems & \multirow{6}{*}{$\begin{array}{l}\text { A general introduction to } \\
\text { forensic psychiatry and } \\
\text { mental health issues }\end{array}$} \\
\hline & & & Referral and procedures & \\
\hline & & & $\begin{array}{l}\text { Difficult psychiatric entities Interface/ } \\
\text { difficulties with } \\
\text { terminology }\end{array}$ & \\
\hline & & & $\mathrm{NPCl}$ & \\
\hline & & & Psychosis & \\
\hline & & & Post-traumatic stress disorder & \\
\hline \multirow[t]{4}{*}{ September 2007} & \multirow[t]{4}{*}{3 days } & 3 psychiatrists & Grouped topics with reference to: & Case studies introduced \\
\hline & & Child psychiatrist & The psychiatrist and the law & \multirow{2}{*}{$\begin{array}{l}\text { Lectures grouped into major } \\
\text { psycho-legal issues }\end{array}$} \\
\hline & & \multirow[t]{2}{*}{ Social worker } & \multirow[t]{2}{*}{ The psychiatrist's role in $\mathrm{NPCl}$} & \\
\hline & & & & $\begin{array}{l}\text { Introduced a visit to psychiatric } \\
\text { hospital after WHFPU presentations }\end{array}$ \\
\hline \multirow[t]{3}{*}{ March 2008} & 3 days & 3 psychiatrists & Previous topics and & \multirow{2}{*}{$\begin{array}{l}\text { More time spent on practical } \\
\text { procedures during visit to hospital }\end{array}$} \\
\hline & \multirow{2}{*}{$\begin{array}{l}\text { Additional workshop } \\
\text { first half of year }\end{array}$} & Child psychiatrist & additional topic: & \\
\hline & & Social worker & Physical illness and substances & One extra topic introduced \\
\hline \multirow[t]{3}{*}{ September 2008} & \multirow[t]{3}{*}{3 days } & $\begin{array}{l}4 \text { psychiatrists } \\
\text { Child psychiatrist }\end{array}$ & $\begin{array}{l}\text { Previous topics in a short overview } \\
\text { and additional topics: }\end{array}$ & $\begin{array}{l}\text { Less time spent on formal lectures } \\
\text { and theory }\end{array}$ \\
\hline & & \multirow{2}{*}{ Social worker } & Mental retardation & Two new topics introduced \\
\hline & & & Personality disorders & $\begin{array}{l}\text { More time dedicated to case studies, } \\
\text { with practical examples of real court } \\
\text { cases provided }\end{array}$ \\
\hline \multirow[t]{6}{*}{ May 2009} & \multirow[t]{6}{*}{3 days } & 4 psychiatrists & \multirow{2}{*}{$\begin{array}{l}\text { Previous topics adjusted with more } \\
\text { theory and additional topics: }\end{array}$} & No social work presentations \\
\hline & & Child psychiatrist & & \multirow{2}{*}{$\begin{array}{l}\text { Brief overview-like presentations } \\
\text { introduced before discussing case } \\
\text { studies }\end{array}$} \\
\hline & & \multirow[t]{4}{*}{2 Psychologists } & $\begin{array}{l}\text { Psychiatrist/psychologist and the } \\
\text { law }\end{array}$ & \\
\hline & & & Personality disorders and & More psychological inputs \\
\hline & & & psychometric testing & Requested a senior prosecutor \\
\hline & & & Mental retardation and IQ tests & $\begin{array}{l}\text { to be present as co-facilitator but } \\
\text { could not be arranged }\end{array}$ \\
\hline \multirow[t]{5}{*}{ September 2009} & \multirow[t]{5}{*}{3 days } & 4 psychiatrists & \multirow{5}{*}{$\begin{array}{l}\text { The basic topics and court cases } \\
\text { remained the same }\end{array}$} & \multirow{2}{*}{$\begin{array}{l}\text { Court cases were grouped according } \\
\text { to the psychiatric diagnostic opinion }\end{array}$} \\
\hline & & Child psychiatrist & & \\
\hline & & \multirow[t]{3}{*}{2 psychologists } & & $\begin{array}{l}\text { The hospital visit moved to the } \\
\text { beginning of the WHFPU's } \\
\text { involvement }\end{array}$ \\
\hline & & & & $\begin{array}{l}\text { A senior advocate from the } \\
\text { prosecutorial offices co-facilitated } \\
\text { and incorporated cross-examination } \\
\text { scenarios }\end{array}$ \\
\hline & & & & Cultural issues not presented \\
\hline
\end{tabular}

is the different procedural and administrative approaches by psychiatrists and hospitals in different regions. Wary and sometimes suspicious attitudes of a few of the prosecutors towards psychiatry changed as their knowledge and insight into psychiatric practice and methods of observation improved.
The psychiatrists' impressions that were considered important to improve the shared knowledge and facilitation at the workshops are listed in Table V. 
Table V. Important issues considered to improve workshop facilitation

Presenting questions, case studies and real court cases

Sufficient Q\&A time

Grouping of major psychiatric entities

Presenting signs and symptoms that a psychiatrist evaluates, as well as the different courses of psychiatric disorder(s)

Input, guidance and co-facilitation by an experienced senior prosecutor The need to know how to lead and cross-examine an expert witness

Inclusion of clinical psychologists

Visit to a psychiatric facility

\section{Discussion}

The importance of evaluating a training programme is mentioned by Linn Hammergren in the paper 'Judicial training and justice reform', in which it is stated how important it is to identify certain goals and to then choose adequate means for pursuing them. ${ }^{8}$ In the assessment of training needs it is important to put greater focus on the practical problems experienced by the prosecutors in their jobs, rather than to try and determine in which areas they lack knowledge. This evaluation should be an ongoing process because it must always be kept in mind that needs and objectives will vary over time.

Information focused on in the review of the workshops included the topics most frequently requested by prosecutors and themes that elicited most questions and discussion during the workshops. Topics that were considered to be problematic areas by either the prosecutors in their written feedback or by the psychiatrists in their observations during the workshops were also highlighted. Other observations by the psychiatrists that were taken into consideration were how certain methods of presentation or facilitation were perceived and whether case studies or formal lectures were preferred.

In the Clinical Handbook of Psychiatry and the Law it is mentioned that when educating the lawyer, the psychiatrist should explain the process of mental illness, the signs and symptoms that constitute the syndrome and the typical course of the illness. ${ }^{4}$ The psychiatrist should clarify how features of the illness may create a specific need for care and treatment and how certain aspects may have particular effects on legal matters. ${ }^{4}$ During the workshops and through interaction with the prosecutors it became clear that these are important aspects to address to improve the prosecutors' overall understanding of psychiatric disorders and their effects on criminal capacity.

One factor highlighted by this review was that certain specific topics were more problematic than others and required more time for discussion. Especially with problematic topics, the presence of a senior, experienced prosecutor may assist in providing more practical examples of how to apply the newly acquired knowledge and how it can be used to prosecute more effectively. Ultimately, it remains the responsibility of the prosecutor to know what information may be sought from a specific expert witness and how to use that information in court.

Previous research by Hillbrand et al. has shown that factors that contribute to successful training sessions include administrative support, use of a multi-modal approach, and the use of small groups. ${ }^{9}$ During the prosecutorial workshops, interactive approaches such as discussion of case studies as practical examples, group discussions with facilitated audience participation, and hospital visits with practical exposure were generally perceived as being the most effective and useful.

Although lawyers are professionals in the field of law, they are usually laypeople when it comes to psychiatric matters. For this reason, the workshops and training sessions are seen as crucial for legal professionals to develop a basic understanding of mental illness and the mental health system and to improve the liaison between the two fields.

\section{Conclusion}

From the references gathered, the general consensus is that mental health service providers can offer law professionals valuable training opportunities with regard to the major mental illnesses and their treatment, course and prognosis. It is important for the trainers to focus on improving law professionals' understanding of how mental illness can affect a person's criminal capacity, or how it can contribute to criminal behaviour. Workshops such as these focus on helping court professionals to be more knowledgeable about mental health and competency issues that they might face during their careers. ${ }^{10}$

The reviewed workshop results indicate there is a need in South Africa for training of prosecutors in mental health topics. The workshops on criminal capacity have grown in popularity. Interactive workshops with case presentations, discussion groups and audience participation, with co-facilitation of a senior, experienced prosecutor, seemed to be the preferred method of training. A visit to a forensic hospital and practical exposure to administrative procedures and psychiatric processes are beneficial.

The ultimate goal of the psychiatrist's involvement in prosecutorial workshops is to work towards a successful collaboration between the criminal justice and mental health systems. This requires a mutual understanding of each discipline's missions and methodologies. Training sessions provide an opportunity for reciprocal sensitisation between the different fields. While psychiatrists are participating in prosecutorial workshops there is an excellent opportunity for court personnel to educate mental health care providers on the functions, concerns, and procedures of the court. For psychiatrists the rewards lie in being helpful to the justice system and in applying psychiatric knowledge a way that enhances the respectability of psychiatry as a whole. 


\section{References}

1. Scheele EM. The medical expert and the prosecutor. U Kan City L Rev 1960:28:123-132.

2. Kaliski S. Psycholegal Assessment in South Africa. 1st ed. Cape Town: Oxford University Press, 2006:3,38,50-54.

3. Gutheil TG. Psychiatric expert witnesses in the new millennium. Psychiatr Clin North Am 2006;29:823-832.

4. Applebaum PS, Gutheil TG. Clinical Handbook of Psychiatry and the Law. 4th ed. Lippincott Williams \& Wilkins, 2007:218-222,262-269.

5. American Academy of Psychiatry and the Law (homepage on internet). Bloomfield: AAPL (updated 2005 May). http://www.ais.up.ac.za/ (accessed February 2009).

6. Resnick PJ. Perceptions of psychiatric testimony: A historical perspective on the hysterical incentive. Bull Am Acad Psychiatry Law 1986;14:209-219.

7. Crisanti AS, Arboleda-Florez J, Stuart H. The Canadian Criminal Code provisions for mentally disordered offenders: A survey of experiences, attitudes and knowledge. Can J Psychiatry 2000;48(9):816-821.

8. Hammergren L. Judicial Training and Justice Reform. US Agency for International Development: Bureau for Global Programmes, Field Support and Research. Washington: USAID, 1998

9. Hillbrand, M, Hawkins D, Howe DM, Stayner D. Through the eyes of another: improving the skill of forensic providers using a consumer-informed role-play procedure. Psychiatr Rehabil J 2008;31(3):239-242

10. Carmi A. On cross examination of expert witnesses. Med Law 1985;4:95-100.
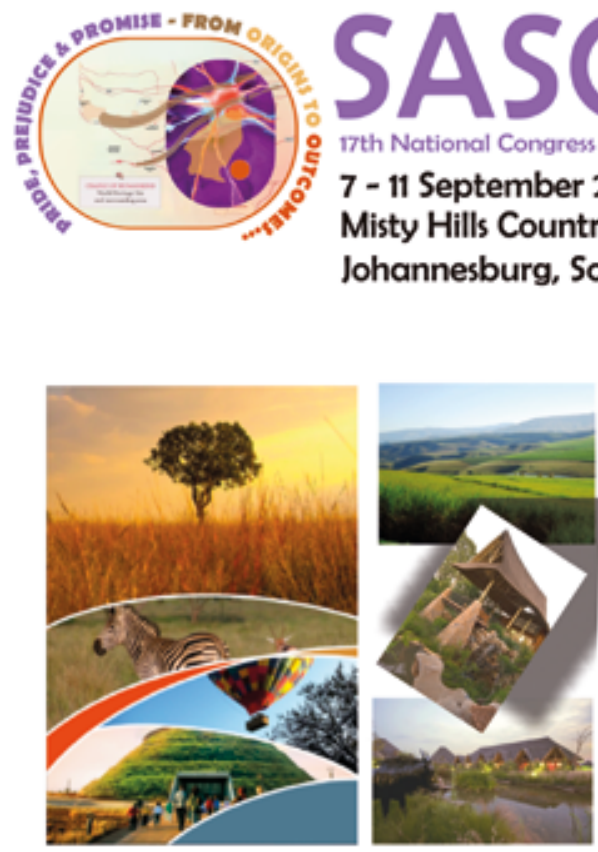

Map to Misty Hills

For information on the hotel please visit the website:

\section{www.mistyhills.co.za}

For information on the Cradle of Humankind please visit the website:

www.cradleofhumankind.co.za

For further information please contact the congress organisers Londocor Event Management on

Tel: +2711 7684355 E-mail: sonja@londocor.co.za / yvonne@londocor.co.za

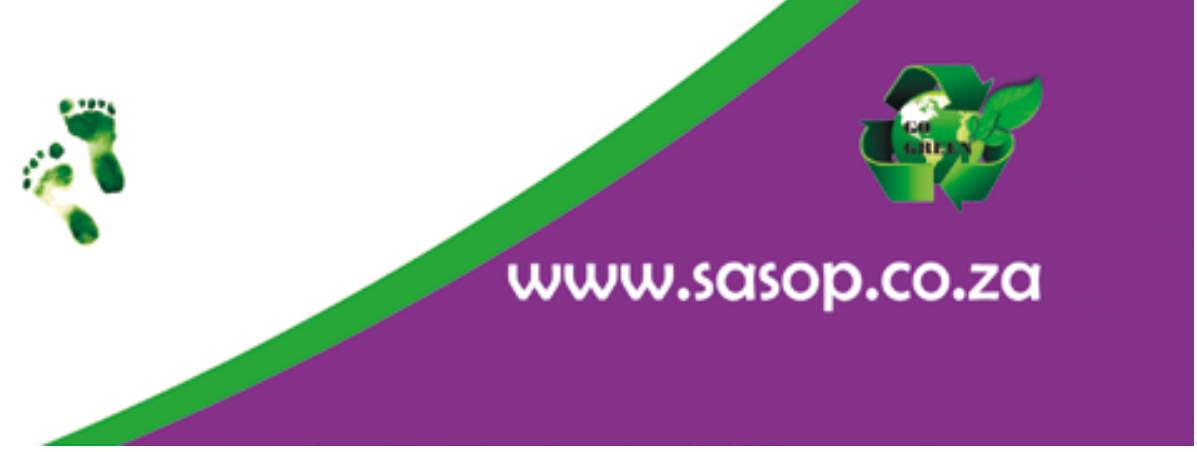

